\title{
Neonatal Vaccination: Challenges and Intervention Strategies
}

\author{
Matthew C. Morris Naveen Surendran \\ Research Institute, Rochester Regional Health Systems, Rochester, N.Y., USA
}

\section{Key Words}

Neonate $\cdot$ Vaccine $\cdot$ Toll-like receptor

\begin{abstract}
Background: While vaccines have been tremendously successful in reducing the incidence of serious infectious diseases, newborns remain particularly vulnerable in the first few months of their life to life-threatening infections. A number of challenges exist to neonatal vaccination. However, recent advances in the understanding of neonatal immunology offer insights to overcome many of those challenges. Objective: This review will present an overview of the features of neonatal immunity which make vaccination difficult, survey the mechanisms of action of available vaccine adjuvants with respect to the unique features of neonatal immunity, and propose a possible mechanism contributing to the inability of neonates to generate protective immune responses to vaccines. Methods: We surveyed recent published findings on the challenges to neonatal vaccination and possible intervention strategies including the use of novel vaccine adjuvants to develop efficacious neonatal vaccines. Results: Challenges in the vaccination of neonates include interference from maternal antibody and excessive skewing towards Th2 immunity, which can be counteracted by the use of proper adjuvants. Conclusion: Synergistic stimulation of multiple Toll-like receptors by incorporating well-
\end{abstract}

defined agonist-adjuvant combinations to vaccines is a promising strategy to ensure a protective vaccine response in neonates.

(c) 2016 S. Karger AG, Basel

\section{Introduction}

High disease burden in early life and recent advances in understanding neonatal immunology have created a renewed interest in neonatal vaccination and adjuvants. Neonates (defined as children less than 4 weeks of age) and young infants are less protected against life-threatening diseases due to lack of vaccines or late administration. For instance, developing a flu vaccine that can be given to infants younger than 6 months of age would significantly reduce worldwide morbidity and mortality from the disease. Recent research indicates that neonatal vaccination may be an effective strategy for protecting against earlylife infections such as influenza, respiratory syncytial virus, and pertussis. Bacillus Calmette-Guerin (BCG), a live vaccine against tuberculosis, demonstrates that a single dose of vaccine administered at birth can in principle confer lifelong protection [1].

Almost all vaccines work through induction of serum or mucosal antibodies, especially in young infants where the lack of previous antigen exposure limits the effective-

\section{KARGER}

E-Mail karger@karger.com

www.karger.com/neo
C) 2016 S. Karger AG, Basel

1661-7800/16/1093-0161\$39.50/0
Naveen Surendran, $\mathrm{PhD}$

Center for Infectious Diseases and Immunology

Rochester General Hospital Research Institute, Rochester Regional Health System 1425 Portland Ave., Rochester, NY 14621 (USA)

E-Mail Naveen.Surendran@ rochesterregional.org 
ness of T-cell responses [2]. Cellular immunity is also required for protection against disseminated disease and recovery from measles and smallpox [3-5]. CD4+ T cells, especially follicular B-helper T cells (TFH), are instrumental in helping B cells to produce antigen-specific antibodies. Also, Th1 - and cytotoxic T lymphocyte-mediated immunity is critical for protection against intracellular infections, as exemplified by the BCG vaccine [6].

Currently, only the hepatitis B (Hep B) vaccine is recommended for administration at birth in the US [7], though the oral polio and BCG vaccines are also given in other parts of the world [8]. The Hep B vaccine contains alum, which is the only approved adjuvant for use in neonatal vaccines due to its established record of safety and its promotion of Th2-mediated antibody responses. The Hep B vaccine confers strong protection, significantly reducing infection rates [9], and has also been shown to have therapeutic value when administered to Hep B-infected infants in conjunction with Hep B immunoglobulin [10]. However, while the Hep B vaccine is satisfactory for protecting neonates, it requires 3 doses, unlike BCG which is protective after only one, and can likely be improved by the incorporation of more potent adjuvants than alum.

Aluminum salts usually do not promote robust Th1 immunity [11], which is a major shortcoming, particularly in the context of neonatal immunity, where there is a pronounced tendency for skewing towards Th2 responses $[1,12]$. Murine studies have shown that neonatal Th1 cells express the IL-4Ra/IL-13R $\alpha$ heteroreceptor, rendering them susceptible to apoptosis mediated by IL4 , a product of Th2 cells [13]. A better adjuvant than alum which can simultaneously stimulate both innate and Th1type immunity will help in the development of protective neonatal vaccines against multiple diseases, and hopefully reduce the number of necessary doses. Combinations of alum with other adjuvants such as CpG oligodeoxynucleotides have shown promise in murine experiments [14], but little research is being done on clinical applications of novel adjuvants in humans. While a search of the National Institutes of Health database (search terms 'neonate' and 'adjuvant', conducted October 2015) revealed several ongoing clinical trials of vaccines for pregnant or postpartum women, there are currently no trials aimed at the introduction of new adjuvants for neonatal vaccines, leaving this need unmet.

Effective neonatal vaccination would be ideal especially for less-privileged infants, for whom birth is often the only contact with health care systems. Neonatal vaccination therefore has the potential to improve vaccine cover- age and confer protection before initial exposure to vaccine-preventable viral and bacterial infections. Alternative, indirect strategies include vaccination of the pregnant mother and/or other family members so as to 'cocoon' the neonate against exposure to pathogens (e.g. expectant mothers in the US are recommended to receive the Tdap and inactivated influenza vaccines [15]), but these strategies have shortcomings. The transfer of maternal antibody depends on factors such as gestational age, maternal antibody level (which in turn depends on pathogen exposure and timing of maternal vaccination), IgG subclass, placental characteristics, and maternal nutrition. Additionally, maternal antibodies interfere with infant vaccine responses and reduce the bioavailability of orally administered vaccines $[16,17]$. Apart from the immunological challenges, cocooning is logistically complicated, limited by safety and medicolegal concerns (e.g. the ethics of mandating vaccination of healthy adults against diseases for which they are not personally at risk), and expensive. Direct vaccination of neonates at birth is therefore to be pursued as the best means of protecting them from infection.

\section{Challenges}

The immune system of neonates differs in many ways from that of older children and adults. In newborns, plasma is rich with immune regulatory factors such as adenosine $[18,19]$. The numbers of antigen-presenting cells (APC) are low, with low basal levels of costimulatory molecules, MHC-II surface expression, and a decreased ability to produce cytokines (particularly IL-12) in response to single Toll-like receptor (TLR) stimulation $[1,20,21]$. Human cord blood CD4+ T cells are enriched in immature recent thymic emigrants and show polarization towards Th2 upon antigen exposure, with low production of Th1 cytokines and a reduced frequency of TFH [1]. At the same time, an abundance of immune-suppressive natural Tregs are active in neonates, secreting large amounts of IL-10 and TGF $\beta$ that induce tolerogenic APCs and suppress effector T-cell responses $[22,23]$. Neonates also respond to immune challenge with qualitatively and quantitatively lower antibody responses [1]: a vaccinated neonate will produce lower antibody titers with less-functional antibody compared to a 2-monthold infant. Defects in plasma cell differentiation have been identified, owing to limited T-cell help [8]. Together, the divergence of neonatal immune responses from older children and adults suggests that neonatal immu- 
nity is tightly regulated to facilitate microbial colonization and to avoid untoward proinflammatory responses, which unfortunately has the additional effect of making them vulnerable to infections.

\section{Neonatal Immunity}

The study of immunology in neonates poses special ethical challenges because of the great vulnerability of this population $[12,24]$. Umbilical cord blood is usually used in experiments, but this is an imperfect reflection of immune function in the first 4 weeks after birth since gut microflora have a tremendous impact on immune system development and are not acquired until after birth [25]. Mice are more readily available for experimentation, but there are important known differences in the course of development during the neonatal period. In mice, 'neonatal' typically refers to the first 7 days after birth, leaving a strictly limited time period for the performance of experiments. These experiments in turn usually continue for weeks to months - well into murine adulthood - with the ultimate result that any findings might not be applicable to human neonates. Furthermore, there is evidence that environmental conditions at birth significantly influence the functioning of human neonatal APCs [26], such that studies performed in industrialized countries may yield different results compared to developing countries. Nevertheless, with these caveats in mind, a body of research has accumulated on the mechanisms of neonatal vaccine responses and possible intervention strategies.

A study of human neonates showed impaired Th1 polarization in response to infection by Staphylococcus species [27], thought to result from programming by the maternal immune system in utero as a safeguard against catastrophic immune reactions, specifically by means of increased prevalence of Tregs [28]. Maternal antibodies transferred through the placenta or in milk also interfere with effective vaccination, as these circulating antibodies can reduce the availability of antigen to the neonate's own immune cells [17], and the neonatal Fc receptor increases the serum half-life of passively transferred antibodies [29]. There are also indications of poor tissue organization in neonatal lymph nodes in mice, with murine B cells generally showing immature phenotypes [28], probably due to the naive state of the neonatal immune system. Maternal antibodies have only minimal effects on T-cell responses as observed with the strong Th1-type immune response generated by neonates after vaccination with BCG [30]. The observed success of neonatal vaccination using Hep B and BCG demonstrates that the adaptive immune systems of neonates are sufficiently strong to generate functionally protective antibody and long-term Tand B-cell memory in response to the proper combinations of vaccine antigens and adjuvants. Thus, the central difficulty with neonatal immune responses likely lies not with the $\mathrm{T}$ and $\mathrm{B}$ lymphocytes, but with the innate immune system. The defective responses of neonatal APC to pattern recognition receptor (PRR) stimulation described below are most likely attributable to the neonatal immune regulatory milieu and can very well be overcome by inducing synergistic signals through multiple PRRs, enabling robust adaptive and memory responses to vaccines. An overview of important cellular interactions for strong vaccine response is presented in figure 1.

A successful vaccine formulation must be able to circumvent or overcome the functional peculiarities of the neonatal period. Research continues to yield insights into early immune ontogeny and neonatal vaccine responses. Translational investigation in this field focuses on modulating neonatal innate immune pathways to overcome subdued Th1 immunity by incorporating safe, potent adjuvants into vaccines.

\section{Adjuvants}

Concerns about efficacy, systemic inflammation, and immune tolerance or autoimmunity hinder the development of neonatal vaccines. A good adjuvant improves protective immune responses, thus sparing costly antigens and doses. Few adjuvants are licensed for use in human vaccines. As of this writing, only vaccines containing simple aluminum salts have been approved for neonates. More complex adjuvants such as AS04 [aluminum hydroxide bound to the monophosphoryl lipid A component of lipopolysaccharide (LPS), produced by GlaxoSmithKline] and AS03 (an oil-in-water emulsion containing vitamin E) have recently been licensed for use in the United States and other countries in vaccines used in infants (beginning at 6 weeks of age), older children, and adults [31], and a few others are being tested or have already been licensed in other parts of the world, particularly the oil-in-water emulsion MF59 (produced by Novartis) [32, 33].

In nature, a pathogen is never encountered as an isolated antigen; instead, a whole bacterial cell or virion possesses a wide variety of specific antigens and pathogenassociated molecular patterns such as LPS or dsRNA. Adjuvants boost the immunogenicity of a killed/attenuated 
Fig. 1. Important cellular interactions during vaccination. The vaccine antigen, in conjunction with TLR ligands and a carrier molecule, promotes secretion of IL-12 and IFNa by DC, which promote Th1 and cytotoxic Tlymphocyte proliferation and IgG secretion.

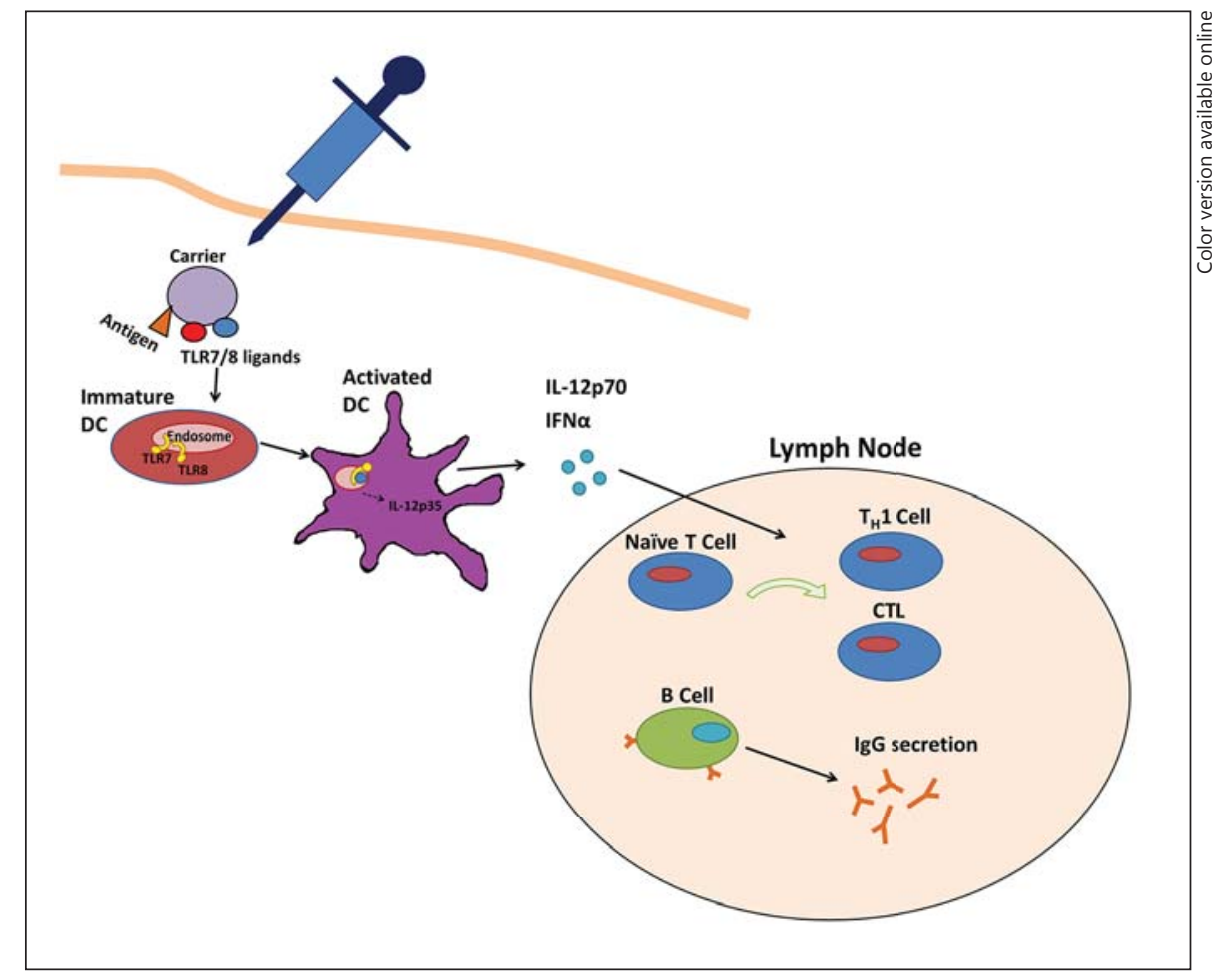

pathogen or isolated antigen by making the immune system treat these more like intact pathogens [31-34]. The immune boosting effect of an adjuvant operates by increasing the half-life of antigen within the recipient or activating innate immunity, while some adjuvants do both [35]. Controlled antigen release (also known as the 'depot effect') depends on binding of adjuvant molecules to antigen molecules within the vaccine preparation. The activity of adjuvants containing aluminum salts depends in part on the creation of such depots [36,37]. Similarly, MF59 assembles antigen-containing microspheres [38] which persist in the tissue significantly longer than antigen alone, prolonging immune stimulation from a single vaccine dose and improving the quality of the response $[32,39]$. Another example is Hep-c, an experimental adjuvant based on the formation of antigen-bearing nanospheres. This was found to improve the immunogenicity of the Hep B vaccine in adult mice, eliciting improved Th1 responses compared to the formulation containing aluminum hydroxide [11].

Novel adjuvants need to combine the safety and antibody induction of alum with superior innate immune potentiation to induce Th1 and TFH cell responses. For example, in addition to the depot effect, MF59 enhances APC migration and survival, maintaining strong B- and
T-cell memory and TFH cell responses with a good safety profile [40]. Adjuvants such as AS04 combine alum with the TLR4 agonist monophosphoryl lipid A, enhancing innate immune responses while maintaining safety [41]. Newer adjuvants should aim to boost vaccine responses by activating innate immune signaling pathways as BCG does. Lactoferrin, a major whey protein component of milk, has been shown to promote dendritic cell (DC) maturation and IL-12 production in neonatal mice model of influenza, and can be considered as a safe adjuvant [42, 43]. In addition to processing antigen into a form recognizable by lymphocytes, APCs also express diverse cytokines and costimulatory molecules which can profoundly influence the course of an immune response [44, 45]. A recent study of plasmacytoid DCs (an important APC population) demonstrated that neonatal $\mathrm{pDCs}$ can drive IFNa-mediated Th1 responses comparable to adults as long as the proper TLR stimulants are included [46]. Synergistic stimulation of DCs with at least 2 TLR agonists has been shown to enhance IL-12p70 secretion from cord blood [20]. IL-12 also mediates DC-directed T-cell differentiation to TFH $[47,48]$, which in turn promote Bcell memory responses, indicating that potentiation of innate cell responses can help overcome adaptive immune deficiencies in neonates. Innate immune response can be 
enhanced by judicious targeting of PRRs. The factors that influence Th1/Th2 skewing include antigen dose, type of adjuvant, and route of administration. Since activation of TFH and Th 1 cells depends strongly on IL-12 $[49,50]$, effective induction of IL-12 is a highly sought goal in vaccine design. Attempts to promote Th1 immunity by targeting antigen directly to DCs have met with some success [50], and other tested adjuvants seek to accomplish this by activating the intracellular signaling networks of APCs. The complement molecule C3d has been used as an adjuvant in adult mice [28], falling into the category of innate immunity activators.

Broadly, innate immune signaling comprises PRR and their downstream effectors. The main PRR of interest in vaccine design are the TLRs and the NOD/inflammasome pathways inside immune cells, which recognize conserved molecular patterns common to different categories of pathogens and trigger the production of cytokines and chemokines (including IL-12) to tune the immune response $[51,52]$. Most TLR signaling depends on the adaptor protein myeloid differentiation primary response 88 (MyD88), which connects receptor ligation to activation of MAPK and NFKB $[51,53]$. Upon testing, many adjuvants have been found to act through MyD88. Heparan sulfate, an endogenous danger signal and TLR4 ligand, promotes DC maturation in a MyD88-dependent fashion [54], and both alum and MF59 have been found to require MyD88 for their adjuvant activity [38] in addition to the establishment of antigen depots. Cyclodextrins, a family of drug delivery systems, have likewise been found to boost vaccine responses both by increasing antigen availability and by signaling through MyD88 to increase the activity of TFHs [54]. Many of these adjuvants activate inflammatory signaling indirectly, as a consequence of tissue damage and the release of danger signals which are themselves PRR ligands. NOD/inflammasome activation and consequent caspase-dependent cytokine secretion is often a consequence of adjuvant-induced cell death [55-57]. Simultaneous activation of multiple PRR appears to be an effective means of overcoming neonatal DC nucleosome remodeling, restoring IL-12p35 production favorable to the development of a Th1 immune response [58], and additionally counteracts the APC tolerance caused by the heightened prevalence of Tregs and other suppressive mechanisms active in neonates.

With the growth of our understanding of innate immune signaling pathways in vaccine responses, directed and evidence-based approaches have become more feasible, leading to the current interest in compounds such as the TLR4 ligand monophosphoryl lipid A $[37,59]$ and the TLR7/8 ligand R848 [20,56]. Continued research will yield more effective, targeted adjuvants, tailored to the specific pathogens against which a vaccine is sought.

\section{Mechanistic Attributes Necessary for an Effective Neonatal Adjuvant}

TLRs can be categorized as endosomal or surface expressed. The difference between the TLRs which function well in neonates and those which do not appears to be that the former (TLR3, TLR7, and TLR8) are located within endosomes, while the latter (most prominently TLR 2 and TLR4) are surface-expressed. This fact is critical for understanding the signaling mechanisms employed by different TLRs. TLR4 is well known to depend on its coreceptor, CD14, for effective signal transduction, particularly with respect to the engagement of TIR-domaincontaining-adaptor inducing interferon- $\beta$ (TRIF)-dependent signaling [51]. Emerging evidence indicates that CD14 also plays an important role in TLR2 signaling. CD14 has been demonstrated to bind TLR2 directly, facilitating ligand transfer [60]. The LPS-binding protein interacts with lipoteichoic acid, similarly bringing it into contact with CD14 and TLR2, and increased lipoteichoic acid binding to CD14 promoted inflammatory cytokine production [61]. In human neonatal cord blood, CD14 levels are generally low compared to adults [62]. This is true specifically on neonatal cord blood monocytes [20], which is particularly suggestive that CD14 deficiency may be an important contributing factor to the impaired neonatal immune response to TLR2 and TLR4 stimulation. In light of this, we can posit a mechanism in which impaired CD14 and MyD88 functioning in neonatal APCs dampens their response to stimulation by TLR2 and TLR4 ligands (fig. 2). The intracellular receptors are not similarly affected: TLR3 because it signals independently of MyD88, relying instead upon a different TLR adaptor, TRIF [63], and TLR7 and TLR8 because they do not require association of CD14. In neonatal mice, TRIF-dependent TLR4 signaling was found to be protective against Gram-negative sepsis, while MyD88-dependent TLR4 signaling was protective in adults [64], indicating that the relationship between these pathways shifts with age.

An important molecule for the regulation of adaptive immunity is the proinflammatory cytokine IL-12. Secreted largely by DCs [65], it promotes the activity of cytotoxic T lymphocytes and Th1 [66], and is also critical for the differentiation of TFHs $[47,48]$. MF59 was recently 
Fig. 2. Proposed mechanism of neonatal APC deficiencies. Surface-expressed TLRs require the activity of CD14 for effective signal transduction, while the endosomal TLRs (TLR3, TLR7, and TLR8) are CD14independent, and can drive effective expression of IL-12 and IFNa in the neonate where CD14 expression is reduced.

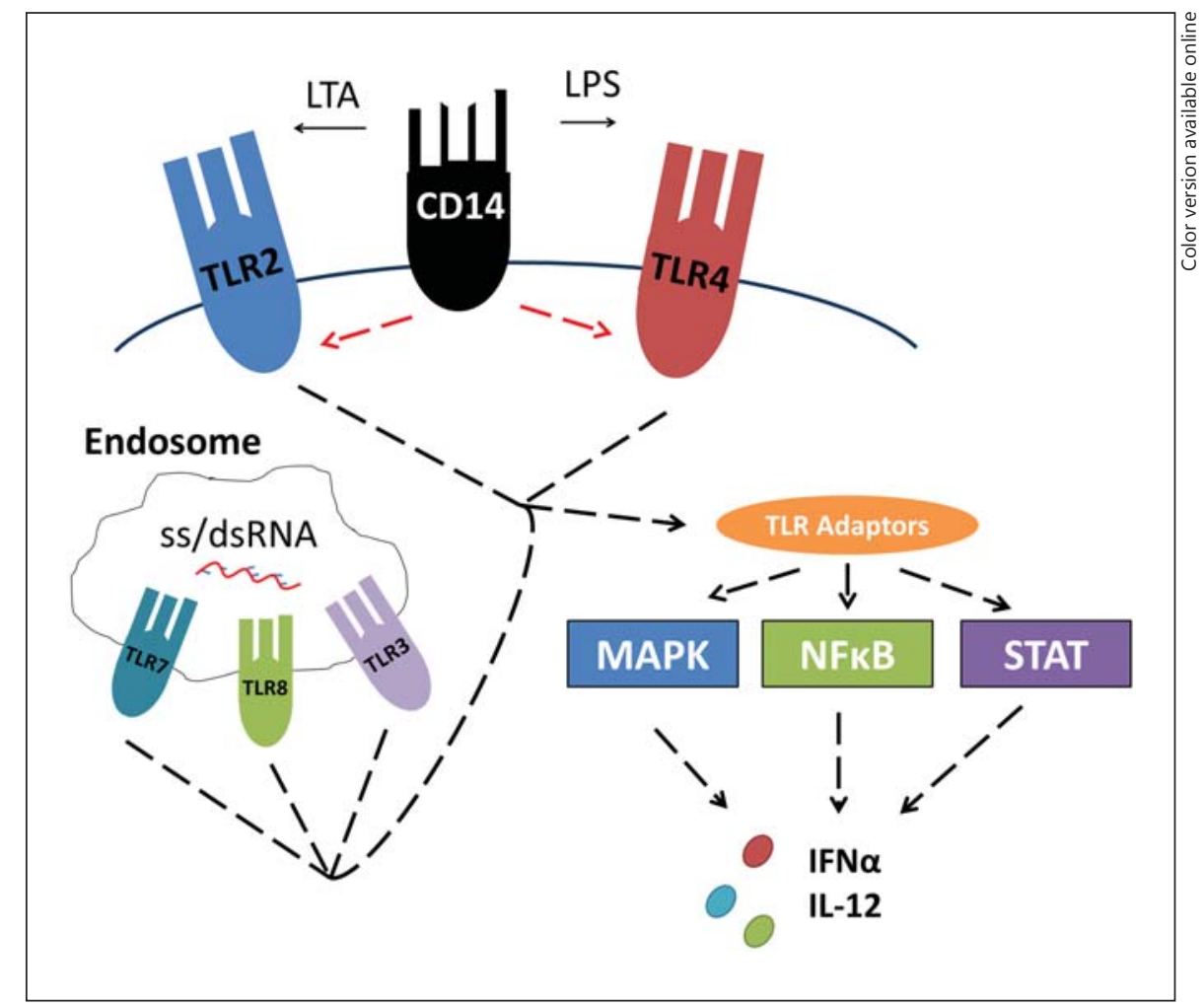

shown to improve vaccine responses of neonatal and infant mice by promoting TFH activity [40]; the mechanism was not conclusively identified but the possibility of IL-12 involvement should not be overlooked. Adenosine, which is abundant in neonatal cord blood [67], is known to suppress TLR-dependent secretion of cytokines including IL-12 [68-70]. It is therefore possible that part of the neonatal deficiency in Th1 polarization arises in part from high concentrations of circulating adenosine. More general defects in TLR signaling also appear to contribute. For example, stimulation of human neonatal DCs with CpG (a TLR9 ligand) results in reduced production of IFNa compared to adults [71]. This is likely a result of defective IRF3 activity (a critical mediator of TLR signaling), which may also contribute to dampened IL-12 production [72]. Deficient IFNa responses from human neonates are also observed in the context of respiratory syncytial virus infection, thought to contribute to the type 2 inflammation associated with a failed respiratory syncytial virus vaccine trial in the 1960s, especially in infants [12]. Human cord blood leukocytes have reduced MyD88 expression, resulting in diminished MAPK activation and IL-12 production upon TLR4 stimulation [67]. A study with ceramide, a ligand of TLR4 [73], found that it was an effective adjuvant for tetanus vaccine responses in young mice (17 days old) but not in neonatal mice, and that inflammatory cytokine production in response to ceramide improved with the age of the mouse, parallel with the LPS response [74]. This is further animal model evidence of neonatal defects in the innate immune signaling pathways downstream of TLRs.

Neonatal responses to stimulation through the intracellular receptors TLR3, TLR7, TLR8, and TLR9 are typically robust. For example, polyinosinic:polycytidylic acid, a ligand for TLR3, together with retinoic acid was found to be an effective adjuvant for the tetanus vaccine in neonatal mice, while polyinosinic:polycytidylic acid alone could promote Th1 activity but not persistent memory [75]. CpG DNA, the definitive TLR9 ligand, improves Th1 activity during infection in neonatal mice, and additionally suppresses IgE production in response to allergen challenge [28]. Neutrophils from neonatal horses were found to produce increased IFN $\gamma$ upon stimulation with CpG DNA [39]. In combination with immune defense peptides and polyphosphazenes (a microsphere-forming synthetic polymer), CpG increased the secretion of antibody against pertussis toxoid after vaccination of both adult and neonatal mice [76]. 
TLR7/8 stimulation has been the subject of much recent interest. These intracellular TLRs predominantly recognize ssRNA, and appear to be highly active in neonates. Unlike TLR4 and TLR2, stimulation of TLR7/8 usually results in robust activation of innate immune signaling in neonates, probably due to their ability to utilize adenosine-refractory intracellular pathways. TLR8 stimulation by $3 \mathrm{M}-002$, a specific ligand, was found to increase expression of proinflammatory cytokines including IL-12 by human cord blood PBMC, raising some responses to levels comparable to adult PBMCs [77]. VTX-294, a synthetic TLR8 ligand, similarly elicited strong cytokine production from human cord blood; human neonatal TNF $\alpha$ and IL- $1 \beta$ production in response to VTX-294 were actually significantly greater than adults' [78]. TLR8 stimulation of neonates is also robust enough to overcome the anti-inflammatory effects of adenosine [56]. R848 (also known as imiquimod) is a ligand for both TLR7 and TLR8. A comparison of specific TLR7 or TLR8 stimulation with simultaneous ligation of both receptors by R848 showed the strongest production of TNFa and IL-1 $\beta$ in response to R848 in human umbilical cord cells [56], indicating both that these signaling pathways function properly in neonates and that simultaneous stimulation of multiple TLRs generates a stronger response than one or another individually.

\section{Conclusion}

To succeed, the vaccination of neonates must overcome two major hurdles. The first is passive immunization from maternal antibodies. This can likely be addressed by novel adjuvant formulae, as shown with some success in the context of a pertussis vaccine by a complex adjuvant formula $[17,76]$. In addition, the ability of the neonatal Fc receptor to prolong the serum half-life of compounds makes it attractive for manipulating vaccine pharmacokinetics [29]. The other major difficulty is inadequate stimulation of type 1 immunity as a result of defective APC responses to PRR ligation. The most effective means of overcoming this defect seems to be simultaneous stimulation of multiple TLRs, especially the intracellular receptors TLR3, TLR7, and TLR8, so as to assist in the promotion of Th1 differentiation by means of increased IL- 12 production $[75,77,78]$. Future studies of neonatal immunity should pay close attention to the different signaling pathways engaged by PRRs and how the functioning of these pathways changes as children age out of the neonatal period. The key to effective vaccina- tion is the effective targeting of these pathways by adjuvants. Although a recent review found no association between oil-in-water or TLR-based adjuvants and the development of autoimmune disease [35], the safety of any new adjuvant will continue to be of paramount concern. The questions of toxicity and possible adverse inflammatory and/or neurological reactions are important, but few clinical data are currently available. The fact that few novel adjuvants have been developed for decades should provide a strong incentive for the pursuit of new formulations. Any experimental adjuvant will require close scrutiny for adverse reactions, as a high degree of safety is necessary to allay parental fears for new adjuvants. If neonatal APCs can be properly activated by the adjuvant within a vaccine, it will be possible to generate a robust vaccine response with durable memory while requiring fewer booster doses with less antigen per dose, reducing cost and increasing the availability of life-saving vaccines.

\section{Acknowledgements}

We thank Dr. Michael E. Pichichero and Dr. Robert Zagursky for their valuable commentaries on the manuscript, and Ted Nicolosi for his assistance with figure preparation.

\section{Disclosure Statement}

The authors report no conflicts of interest. This work was supported by NIH NIAID R03 AI11700-01 to Naveen Surendran.

\section{References}

1 Basha S, Surendran N, Pichichero M: Immune responses in neonates. Expert Rev Clin Immunol 2014;10:1171-1184.

2 Plotkin SA: Vaccines: correlates of vaccineinduced immunity. Clin Infect Dis 2008;47: 401-409.

3 Permar SR, Klumpp SA, Mansfield KG, Kim WK, Gorgone DA, Lifton MA, Williams KC, Schmitz JE, Reimann KA, Axthelm MK, Polack FP, Griffin DE, Letvin NL: Role of CD8+ lymphocytes in control and clearance of measles virus infection of rhesus monkeys. J Virol 2003;77:4396-4400.

4 Permar SR, Moss WJ, Ryon JJ, Douek DC, Monze M, Griffin DE: Increased thymic output during acute measles virus infection. J Virol 2003;77:7872-7879.

5 Slifka MK: Immunological memory to viral infection. Curr Opin Immunol 2004;16:443450 
6 Fletcher HA: Correlates of immune protection from tuberculosis. Curr Mol Med 2007;7: 319-325.

7 Strikas RA; Centers for Disease Control and Prevention (CDC), Advisory Committee on Immunization Practices (ACIP), ACIP Child/ Adolescent Immunization Work Group: Advisory committee on immunization practices recommended immunization schedules for persons aged 0 through 18 years - United States, 2015. MMWR Morb Mortal Wkly Rep 2015;64:93-94.

8 Wood N, Siegrist CA: Neonatal immunization: where do we stand? Curr Opin Infect Dis 2011:24:190-195.

9 Myers HI, Spracklen CN, Ryckman KK, Murray JC: A retrospective study of administration of vaccination for hepatitis B among newborn infants prior to hospital discharge at a Midwestern tertiary care center. Vaccine 2015;33:2316-2321.

10 Cao LH, Liu ZM, Zhao PL, Sun SC, Xu DB, Shao MH, Zhang JD: Efficacy of combined hepatitis B immunoglobulin and hepatitis B vaccine in blocking father-infant transmission of hepatitis B viral infection. Genet Mol Res 2015;14:4651-4657.

11 Fakharzadeh S, Kalanaky S, Hafizi M, Goya MM, Masoumi Z, Namaki S, Shakeri N, Abbasi M, Mahdavi M, Nazaran MH: The new nano-complex, Hep-c, improves the immunogenicity of the hepatitis $B$ vaccine. Vaccine 2013;31:2591-2597.

12 Lambert L, Sagfors AM, Openshaw PJ, Culley FJ: Immunity to RSV in early-life. Front Immunol 2014;5:466.

13 Zaghouani H, Hoeman CM, Adkins B: Neonatal immunity: faulty $\mathrm{T}$-helpers and the shortcomings of dendritic cells. Trends Immunol 2009;30:585-591.

14 Locht C, Mielcarek N: New pertussis vaccination approaches: en route to protect newborns? FEMS Immunol Med Microbiol 2012; 66:121-133.

15 Guidelines for Vaccinating Pregnant Women. Atlanta, CDC, 2014. http://www.cdc.gov/ vaccines/pubs/preg-guide.htm.

16 Dorea JG: Breast-feeding and responses to infant vaccines: constitutional and environmental factors. Am J Perinatol 2012;29:759775.

17 Polewicz M, Gracia A, Garlapati S, van Kessel J, Strom S, Halperin SA, Hancock RE, Potter AA, Babiuk LA, Gerdts V: Novel vaccine formulations against pertussis offer earlier onset of immunity and provide protection in the presence of maternal antibodies. Vaccine 2013;31:3148-3155.

18 Levy O: Innate immunity of the newborn: basic mechanisms and clinical correlates. Nat Rev Immunol 2007;7:379-390.

19 Belderbos ME, Levy O, Meyaard L, Bont L: Plasma-mediated immune suppression: a neonatal perspective. Pediatr Allergy Immunol 2013;24:102-113.
20 Krumbiegel D, Zepp F, Meyer CU: Combined Toll-like receptor agonists synergistically increase production of inflammatory cytokines in human neonatal dendritic cells. Hum Immunol 2007;68:813-822.

21 Moingeon P: Adjuvants for allergy vaccines Hum Vaccin Immunother 2012;8:14921498.

22 Burt TD: Fetal regulatory T cells and peripheral immune tolerance in utero: implications for development and disease. Am J Reprod Immunol 2013;69:346-358.

23 Michaelsson J, Mold JE, McCune JM, Nixon DF: Regulation of $\mathrm{T}$ cell responses in the developing human fetus. J Immunol 2006;176: 5741-5748.

24 Pichichero ME: Challenges in vaccination of neonates, infants and young children. Vaccine 2014;32:3886-3894.

25 Basu S: Neonatal sepsis: the gut connection. Eur J Clin Microbiol Infect Dis 2015;34:215222.

26 Lisciandro JG, Prescott SL, Nadal-Sims MG, Devitt CJ, Richmond PC, Pomat W, Siba PM, Holt PG, Strickland DH, van den Biggelaar $\mathrm{AH}$ : Neonatal antigen-presenting cells are functionally more quiescent in children born under traditional compared with modern environmental conditions. J Allergy Clin Immunol 2012;130:1167-1174.e10.

27 Power Coombs MR, Kronforst K, Levy O: Neonatal host defense against staphylococcal infections. Clin Dev Immunol 2013;2013: 826303.

28 de Brito CA, Goldoni AL, Sato MN: Immune adjuvants in early life: targeting the innate immune system to overcome impaired adaptive response. Immunotherapy 2009;1:883-895.

29 Pyzik M, Rath T, Lencer WI, Baker K, Blumberg RS: FcRn: the architect behind the immune and nonimmune functions of IgG and albumin. J Immunol 2015;194:4595-4603.

30 Marchant A, Goetghebuer T, Ota MO, Wolfe I, Ceesay SJ, De Groote D, Corrah T, Bennett S, Wheeler J, Huygen K, Aaby P, McAdam KP, Newport MJ: Newborns develop a Th1type immune response to Mycobacterium bovis Bacillus Calmette-Guerin vaccination. J Immunol 1999;163:2249-2255.

31 Vaccine safety and availability - common ingredients in U.S. licensed vaccines. Silver Spring, US Food and Drug Administration, 2014. http://www.fda.gov/BiologicsBloodVaccines/SafetyAvailability/VaccineSafety/ ucm187810.htm.

32 Pichichero ME: Improving vaccine delivery using novel adjuvant systems. Hum Vaccin 2008;4:262-270.

33 Heikkinen T, Young J, van Beek E, Franke H, Verstraeten T, Weil JG, Della Cioppa G: Safety of MF59-adjuvanted A/H1N1 influenza vaccine in pregnancy: a comparative cohort study. Am J Obstet Gynecol 2012;207:177.e1177.e8.
34 Griffiths KL, Khader SA: Novel vaccine approaches for protection against intracellular pathogens. Curr Opin Immunol 2014;28:5863.

35 van der Laan JW, Gould S, Tanir JY, ILSI HESI Vaccines and Adjuvants Safety Project Committee: Safety of vaccine adjuvants: focus on autoimmunity. Vaccine 2015;33:15071514.

36 Marrack P, McKee AS, Munks MW: Towards an understanding of the adjuvant action of aluminium. Nat Rev Immunol 2009;9:287293.

37 Brito LA, Malyala P, O’Hagan DT: Vaccine adjuvant formulations: a pharmaceutical perspective. Semin Immunol 2013;25:130-145.

38 Egli A, Santer D, Barakat K, Zand M, Levin A, Vollmer M, Weisser M, Khanna N, Kumar D, Tyrrell L, Houghton M, Battegay M, O'Shea D: Vaccine adjuvants - understanding molecular mechanisms to improve vaccines. Swiss Med Wkly 2014;144:w13940.

39 Cohen ND, Bourquin JR, Bordin AI, Kuskie KR, Brake CN, Weaver KB, Liu M, Felippe $\mathrm{MJ}$, Kogut $\mathrm{MH}$ : Intramuscular administration of a synthetic $\mathrm{CpG}$-oligodeoxynucleotide modulates functional responses of neutrophils of neonatal foals. PLoS One 2014;9: e109865.

40 Mastelic Gavillet B, Eberhardt CS, Auderset F, Castellino F, Seubert A, Tregoning JS, Lambert PH, de Gregorio E, Del Giudice G, Siegrist CA: MF59 mediates its B cell adjuvanticity by promoting $\mathrm{T}$ follicular helper cells and thus germinal center responses in adult and early life. J Immunol 2015.

$41 \mathrm{He}$ P, Zou Y, Hu Z: Advances in aluminum hydroxide-based adjuvant research and its mechanism. Hum Vaccin Immunother 2015; 11:477-488.

42 Sherman MP, Adamkin DH, Radmacher PG, Sherman J, Niklas V: Protective proteins in mammalian milks. NeoReviews 2012;13: e293-e300.

43 Sherman MP, Pritzl CJ, Xia C, Miller MM, Zaghouani $\mathrm{H}, \mathrm{Hahm}$ B: Lactoferrin acts as an adjuvant during influenza vaccination of neonatal mice. Biochem Biophys Res Comm 2015; 467:766-770.

44 Berglund LJ, Avery DT, Ma CS, Moens L, Deenick EK, Bustamante J, Boisson-Dupuis S, Wong M, Adelstein S, Arkwright PD, Bacchetta R, Bezrodnik L, Dadi H, Roifman CM, Fulcher DA, Ziegler JB, Smart JM, Kobayashi M, Picard C, Durandy A, Cook MC, Casanova JL, Uzel G, Tangye SG: IL-21 signalling via Stat 3 primes human naive $B$ cells to respond to IL-2 to enhance their differentiation into plasmablasts. Blood 2013;122:3940-3950.

45 Takaki H, Takeda M, Tahara M, Shingai M, Oshiumi H, Matsumoto M, Seya T: The MyD88 pathway in plasmacytoid and CD4+ dendritic cells primarily triggers type I IFN production against measles virus in a mouse infection model. J Immunol 2013;191:47404747. 
46 Zhang X, Casartelli N, Lemoine S, Mozeleski B, Azria E, Le Ray C, Schwartz O, Launay O, Leclerc C, Lo-Man R: Plasmacytoid dendritic cells engagement by influenza vaccine as a surrogate strategy for driving T-helper type 1 responses in human neonatal settings. J Infect Dis 2014;210:424-434.

47 Schmitt N, Bustamante J, Bourdery L, Bentebibel SE, Boisson-Dupuis S, Hamlin F, Tran MV, Blankenship D, Pascual V, Savino DA, Banchereau J, Casanova J-L, Ueno H: IL-12 receptor $\beta 1$ deficiency alters in vivo $\mathrm{T}$ follicular helper cell response in humans. Blood 2013;121:3375-3385.

$48 \mathrm{Ma}$ CS, Suryani S, Avery DT, Chan A, Nanan R, Santner-Nanan B, Deenick EK, Tangye SG: Early commitment of naive human CD4(+) T cells to the $\mathrm{T}$ follicular helper $(\mathrm{T}(\mathrm{FH})$ ) cell lineage is induced by IL-12. Immunol Cell Biol 2009;87:590-600.

49 Palucka K, Banchereau J: Human dendritic cell subsets in vaccination. Curr Opin Immunol 2013;25:396-402.

50 Cohn L, Delamarre L: Dendritic cell-targeted vaccines. Front Immunol 2014;5:255

51 Morris MC, Gilliam EA, Li L: Innate immune programing by endotoxin and its pathological consequences. Front Immunol 2014;5:680.

52 Akira S: Innate immunity and adjuvants. Philos Trans R Soc Lond B Biol Sci 2011;366: 2748-2755.

53 Xi CX, Xiong F, Zhou Z, Mei L, Xiong WC: Pyk2 interacts with MyD88 and regulates MyD88-mediated NF-kappaB activation in macrophages. J Leukoc Biol 2010;87:415-423.

54 Wu M, Wang H, Shi J, Sun J, Duan Z, Li Y, Li J, Hu N, Wei Y, Chen Y, Hu Y: Gene expression profiles identify both MyD88-independent and MyD88-dependent pathways involved in the maturation of dendritic cells mediated by heparan sulfate: a novel adjuvant. Hum Vaccin Immunother 2014;10: 3711-3721.

55 Maisonneuve C, Bertholet S, Philpott DJ, De Gregorio E: Unleashing the potential of NOD- and Toll-like agonists as vaccine adjuvants. Proc Natl Acad Sci USA 2014;111: 12294-12299.

56 Philbin VJ, Dowling DJ, Gallington LC, Cortes G, Tan Z, Suter EE, Chi KW, Shuckett A, Stoler-Barak L, Tomai M, Miller RL, Mansfield $\mathrm{K}$, Levy O: Imidazoquinoline Toll-like receptor 8 agonists activate human newborn monocytes and dendritic cells through adenosine-refractory and caspase-1-dependent pathways. J Allergy Clin Immunol 2012;130: 195-204.e199.

57 Norton EB, Bauer DL, Weldon WC, Oberste MS, Lawson LB, Clements JD: The novel adjuvant dmLT promotes dose sparing, mucosal immunity and longevity of antibody responses to the inactivated polio vaccine in a murine model. Vaccine 2015;33:1909-1915.

58 Perez O, Romeu B, Cabrera O, Gonzalez E, Batista-Duharte A, Labrada A, Perez R, Reyes LM, Ramirez W, Sifontes S, Fernandez N, Lastre M: Adjuvants are key factors for the development of future vaccines: lessons from the Finlay Adjuvant Platform. Front Immunol 2013;4:407.

59 Aryan Z, Holgate ST, Radzioch D, Rezaei N: A new era of targeting the ancient gatekeepers of the immune system: Toll-like agonists in the treatment of allergic rhinitis and asthma. Int Arch Allergy Immunol 2014;164:46-63.

60 Raby AC, Holst B, Le Bouder E, Diaz C, Ferran E, Conraux L, Guillemot JC, Coles B, KiftMorgan A, Colmont CS, Szakmany T, Ferrara P, Hall JE, Topley N, Labeta MO: Targeting the TLR co-receptor CD14 with TLR2-derived peptides modulates immune responses to pathogens. Sci Transl Med 2013;5: 185 ra164.

61 Kwak MS, Lim M, Lee YJ, Lee HS, Kim YH, Youn JH, Choi JE, Shin JS: HMGB1 binds to lipoteichoic acid and enhances TNF- $\alpha$ and IL-6 production through HMGB1-mediated transfer of lipoteichoic acid to CD14 and TLR2. J Innate Immun 2015;7:405-416.

62 Futata EA, Fusaro AE, de Brito CA, Sato MN: The neonatal immune system: Immunomodulation of infections in early life. Expert Rev Anti Infect Ther 2012;10:289-298.

63 Carty M, Goodbody R, Schroder M, Stack J, Moynagh PN, Bowie AG: The human adaptor SARM negatively regulates adaptor protein TRIF-dependent Toll-like receptor signaling. Nat Immunol 2006;7:1074-1081.

64 Cuenca AG, Joiner DN, Gentile LF, Cuenca AL, Wynn JL, Kelly-Scumpia KM, Scumpia PO, Behrns KE, Efron PA, Nacionales D, Lui C, Wallet SM, Reeves WH, Mathews CE Moldawer LL: TRIF-dependent innate immune activation is critical for survival to neonatal Gram-negative sepsis. J Immunol 2015; 194:1169-1177.

65 Saito Y, Yanagawa Y, Kikuchi K, Iijima N, Iwabuchi K, Onoe K: Low-dose lipopolysaccharide modifies the production of IL-12 by dendritic cells in response to various cytokines. J Clin Exp Hematop 2006;46:31-36.

66 Schmitt N, Ueno H: Regulation of human helper $\mathrm{T}$ cell subset differentiation by cytokines. Curr Opin Immunol 2015;34:130-136.

67 Cuenca AG, Wynn JL, Moldawer LL, Levy O: Role of innate immunity in neonatal infection. Am J Perinatol 2013;30:105-112.

68 Morris MC, Gilliam EA, Button J, Li L: Dynamic modulation of innate immune response by varying dosages of lipopolysaccha- ride (LPS) in human monocytic cells. J Biol Chem 2014;289:21584-21590.

69 Ferrante CJ, Pinhal-Enfield G, Elson G, Cronstein BN, Hasko G, Outram S, Leibovich SJ: The adenosine-dependent angiogenic switch of macrophages to an M2-like phenotype is independent of interleukin-4 receptor alpha (IL-4Ralpha) signaling. Inflammation 2013. 36:921-931.

70 Pernet E, Brunet J, Guillemot L, Chignard M, Touqui L, Wu Y: Staphylococcus aureus adenosine inhibits sPLA2-IIA-mediated host killing in the airways. J Immunol 2015; 194 : 5312-5319.

71 De Wit D, Olislagers V, Goriely S, Vermeulen F, Wagner H, Goldman M, Willems F: Blood plasmacytoid dendritic cell responses to $\mathrm{CpG}$ oligodeoxynucleotides are impaired in human newborns. Blood 2004;103:10301032.

72 Goriely S, Goldman M: From tolerance to autoimmunity: is there a risk in early life vaccination? J Comp Pathol 2007;137(suppl 1): S57-S61.

73 Fischer H, Ellstrom P, Ekstrom K, Gustafsson L, Gustafsson M, Svanborg C: Ceramide as a TLR4 agonist; a putative signalling intermediate between sphingolipid receptors for microbial ligands and TLR4. Cell Microbiol 2007;9: 1239-1251.

74 Chen Q, Ross AC: Alpha-galactosylceramide stimulates splenic lymphocyte proliferation in vitro and increases antibody production in vivo in late neonatal-age mice. Clin Exp Immunol 2015;179:188-196.

$75 \mathrm{Ma} \mathrm{Y}$, Ross AC: The anti-tetanus immune response of neonatal mice is augmented by retinoic acid combined with polyriboinosinic: polyribocytidylic acid. Proc Natl Acad Sci USA 2005;102:13556-13561.

76 Gracia A, Polewicz M, Halperin SA, Hancock RE, Potter AA, Babiuk LA, Gerdts V: Antibody responses in adult and neonatal BALB/C mice to immunization with novel Bordetella pertussis vaccine formulations. Vaccine 2011; 29:1595-1604.

77 Corbett NP, Blimkie D, Ho KC, Cai B, Sutherland DP, Kallos A, Crabtree J, ReinWeston A, Lavoie PM, Turvey SE, Hawkins NR, Self SG, Wilson CB, Hajjar AM, Fortuno ES 3rd, Kollmann TR: Ontogeny of Toll-like receptor mediated cytokine responses of human blood mononuclear cells. PLoS One 2010;5:e15041.

78 Dowling DJ, Tan Z, Prokopowicz ZM, Palmer CD, Matthews MA, Dietsch GN, Hershberg RM, Levy O: The ultra-potent and selective TLR8 agonist VTX-294 activates human newborn and adult leukocytes. PLoS One 2013; 8:e58164. 